\section{ÍNDICE REMISSIVO}

\begin{tabular}{l} 
ÁREAS DE AÇÃo GoVERNAMENTAL \\
\hline \\
-Abastecimento-101-102 \\
-Agropecuária e Pesca-134-135 \\
-Assistência Social-92-101 \\
-Cidadania e Direitos Humanos-103-132 \\
-Ciência e Tecnologia-131 \\
-Consórcios Intermunicipais-37 \\
-Consumidor-131 \\
-Controle de Poluição-46-48 \\
-Criança e Adolescente-104-123 \\
-Cultura, Patrimônio Histórico E Artistico-83-87 \\
-Deficiente-128-130 \\
-Desenvolvimento e Administração De Pessoal-39-40 \\
-Desenv. Regional e Local Em Base Sutentável-135- \\
138 \\
-Educação-51-69 \\
-Energia e Recursos Minerais-42 \\
-Finanças e Orçamento Público-35--36 \\
-Formação de Mão-de-Obra e Geraç. de Emp. e \\
Renda-139-142 \\
-Formas de Gestão E Planejamento-34-35 \\
-Habitação-81-82 \\
-Idoso-123-126 \\
-Indústria, Comércio, Serviços-134 \\
-Judiciário-145 \\
-Lazer e Esportes-88-90 \\
-Limpeza Pública e Sistemas de Coleta, Tratamento e \\
Destinação Final do Lixo-47-48 \\
-Melhoria das Condições e Relações de Trabalho-143 \\
-Minorias-131-132 \\
-Mulher-126-128 \\
-Participação Popular-37-39 \\
-Preservação de Ecossistemas e Reflorestamento- \\
48-50 \\
-Recursos Hidricos, Irrigação e Drenagem-46 \\
-Relaçōes Intergovernamentais-35 \\
-Saneamento-41-42 \\
-Saúde-69-80 \\
-Segurança Pública e Policiamento-90-92 \\
-Sistemas de Informação-36-37 \\
-Telecomunicaçōes-43 \\
-Trânsito e Vias Públicas-42-43 \\
-Transporte Público-82-83 \\
-Urbanismo, Uso e Ocupação do Solo-43-46 \\
\hline
\end{tabular}

FINALISTAS, PRÉ-FINALISTAS E SEMIFINALISTAS SEGUNDO LOCAL E NIVEL DE GOVERNO

Finalistas

Aracruz, ES, Municipal - 59

Belém, PA, Municipal - 140

Birigüi, SP, Estadual - 132

Curitiba, PR, Municipal - 71

Illha Comprida, SP, Municipal - 137

Lagarto, SE, Municipal - 100

Londrina, PR, Estadual - 77

Mossoró, RN, Municipal - 42

Nazareno, MG, Municipal - 59

Pão de Açucar, AL, Municipal - 140

Pedras de Fogo, PB, Municipal - 72

Piraí, RJ, Municipal - 136

Quixeramobim, CE, Municipal - 46

Santa Cruz do Sul, RS, Municipal - 81

São Luis, MA, Intermunicipal - 37

Três Lagoas, MS, Municipal - 95

Macapá, AP, Estadual - 103

Macapá, AP, Estadual - 136

São Paulo, SP, Estadual - 129

São Gabriel da Cachoeira, AM, Indigena - 135
Pré-Finalistas

Piracicaba, SP, Estadual - 141

Santo André, SP, Intermunicipal - 136

Maceió, AL, Municipal - 142

Belo Horizonte, MG, Municipal - 52

Belo Horizonte, MG, Municipal - 117

Camaragibe, PE, Municipal - 36

Paranavaí, PR, Municipal - 97

Lagarto, SE, Municipal - 78

Sāo Bernardo do Campo, SP, Municipal - 44

\section{SEMI-FINALISTAS}

Araguari, MG, Estadual - 63

Belo Horizonte, MG, Estadual - 138

Campo Grande, MS, Estadual - 34

Campo Grande, MG, Estadual - 139

Feira de Santana, BA, Estadual - 137

Fortaleza, CE, Estadual - 128

Goiânia, GO, Estadual - 33

João Pessoa, PB, Estadual - 134

Londrina, PR, Estadual - 133

Macapá, AP, Estadual - 77

Marilia, SP, Estadual - 68

Porto Alegre, RS, Estadual - 35

São Paulo, SP, Estadual - 40

São Paulo, SP, Estadual - 71

São Paulo, SP, Estadual - 103

São Paulo, SP, Estadual - 131

São Paulo, SP, Estadual - 139

Cacoal, RO, Indigena - 135

Ji Paraná, RO, Indigena - 131

Araguacema, TO, Municipal - 138

Belém, PA, Municipal - 127

Belo Horizonte, MG, Municipal - 38

Belo Horizonte, MG, Municipal - 83

Belo Horizonte, MG, Municipal - 124

Belo Horizonte, MG, Municipal - 124

Belo Horizonte, MG, Municipal - 136

Belo Horizonte, MG, Municipal -

Blumenau, SC, Municipal - 129

Cabo de Santo Agostinho, PE, Municipal -

Camaragibe, PE, Municipal - 121

Caraguatatuba, SP, Municipal - 87

Caxias do Sul, RS, Municipal - 97

Chapecó, SC, Municipal - 102

Chapecó, SC, Municipal - 135

Chapecó, SC, Municipal - 135

Curitiba, PR, Municipal - 35

Curitiba, PR, Municipal, -

Diadema, SP, Municipal - 78

Dourados, MS, Municipal - 36

Fortaleza, CE, Municipal - 111

Fortaleza, CE, Municipal - 135

Lauro de Freitas, BA, Municipal - 88

Luzerna, SC, Municipal - 134

Monteiro, PB, Municipal - 76

Pedras de Fogo, PB, Municipal - 72

Penápolis, SP, Municipal - 51

Pirambu, SE, Municipal - 101

Porto Alegre, RS, Estadual - 37

Porto Alegre, RS, Municipal - 44

Porto Alegre, RS,Municipal - 46

Porto Alegre, RS, Municipal - 49

Porto Alegre, RS, Municipal - 74

Porto Alegre, RS, Municipal - 98

Porto Alegre, RS, Municipal - 135

Quissamã, RJ, Municipal - 110

Ribeirão Pires, SP, Municipal - 103

Rolante, RS, Municipal - 83

Santo André, SP, Municipal - 36

Santo André, SP, Municipal - 81

Santos, SP, Municipal - 119

Santos, SP, Municipal - 119

Santos, SP, Municipal - 119

São Bernardo do Campo, SP, Municipal - 44

São Bernardo do Campo, SP, Municipal - 137 
São José do Rio Preto, SP, Municipal - 138

Sobradinho, RS, Municipal - 137

Teresina, PI, Municipal - 44

Vitória, ES, Municipal - 137

Vitória da Conquista ,BA, Municipal - 75

Volta Redonda, RJ, Municipal - 136

NIVEL DO GOVERNO OU ÂMBITO DO PROGRAMA SEGUNDO AS UNIDADES DA FEDERAÇÃO

Nivel Distrital

Distrito Federal - 93, 120

Nivel Estadual

Acre $-131,143$

Amapá - 77, 103,136, 138, 143

Bahia $-47,49,70,71,137$

Ceará $-41,98,99,112,128$

Espirito Santo - 91

Goiás - 33, 39

Minas Gerais - 54, 63, 64, 75, 92, 138

Mato Grosso do Sul - 33, 34,42, 139

Pará - 76, 78, 109, 131

Paraiba - 134

Paraná - 52, 70, 77, 109, 122, 133

Pernambuco - 117

Piaui - 114

Rio de Janeiro - 36, 133

Rio Grande do Sul - 35, 43, 80, 83, 91, 103

Santa Catarina - 41

São Paulo - $33,34,35,40,45,46,53,58,64,68,70$,

$75,77,79,82,90,91,92,103,107,108,116,121$

$129,130,131,132,135,141,143$

Sergipe - 74

Tocantins -66

Nive; Municipal

Alagoas- 140,142

Amazonas-54

Bahia - 39, 44, 45, 55, 61, 70, 75, 88, 89, 99, 103, 107 , $115,125,138,140$

Ceará - 46, 60, 71, 94, 97, 110, 111, 114, 115, 127

135,141

Espirito Santo - 37, 47, 48, 59, 64, 81, 95, 97, 98, 99,

$114,115,122,125,126,137$

Goiás - 125

Minas Gerais - 35, 39, 41, 47, 50, 52, 53, 59, 60, 61,

$62,63,64,65,66,69,75,78,79,80,81,82,83,86$,

$87,88,90,95,96,101,104,107,110,113,116$

$117,121,123,124,126,128,137,140,141$

Maranhão-37, 143

Mato Grosso do Sul - 36, 94, 98, 101, 139, 139

Pará - 59, 73, 76, 89, 113, 114, 127, 140

Paraiba - 54, 56, 62, 72, 76, 81, 84, 89, 94, 110, 139,

145

Paraná - 38, 40, 43, 45, 46, 47, 48, 49, 51, 55, 60, 62 , $65,67,68,69,70,71,73,76,77,80,83,92,94,97$, $99,106,118,120,122,125,127,129,133,134$ $137,139,140$

Pernambuco - 36, 45, 75, 92, 99, 108, 115, 116, 120 , $121,125,127$

Piaui - 44, 103, 104, 123

Rio de Janeiro - 34, 35, 38, 40, 54, 56, 57, 58, 65, 71 $73,74,75,77,80,87,89,99,107,109,110,128$, 131,137

Rio Grande do Norte-42, 46, 88, 126

Rio Grande do Sul - 38, 39, 41, 42, 43, 44, 46, 47, 49 $51,54,56,58,60,63,65,66,67,73,74,78,80,81$, $83,84,85,87,88,94,97,98,106,109,110,112$, $118,121,123,134,135,137,141,142$

Santa Catarina $-45,47,48,49,50,52,53,55,56,57$, $60,64,66,67,69,72,79,84,85,86,87,91,93,95$ $102,104,105,107,108,111,112,113,114,115$,

$117,123,124,126,129,134,135,137,139$
São Paulo - 33, 36, 37, 38, 39, 41, 42, 43, 44, 47, 48, 51, 52, 53, 55 $58,61,62,63,64,65,66,67,68,69,70,71,72,74,75,76,77$.

$78,79,81,82,83,86,87,89,92,93,96,99,100,101,103,104$ $105,106,107,108,112,116,117,118,119,120,121,122,123$ $124,125,126,127,128,129,130,132,133,135,136,137,138$

$139,140,141,142,143$

Sergipe-72, 77, 79, 100, 101

Tocantins - 106, 123, 139

\section{Organização Indigena}

Amazonas - 135

Rondônia - 131, 135

São Paulo - 135

UNIDADES DA FEDERAÇÃO E NÍVEL DE GOVERNO OU ÂMBITO DO PROGRAMA SEGUNDO A LOCALIDADE ONDE SÃO DESENVOLVIDOS

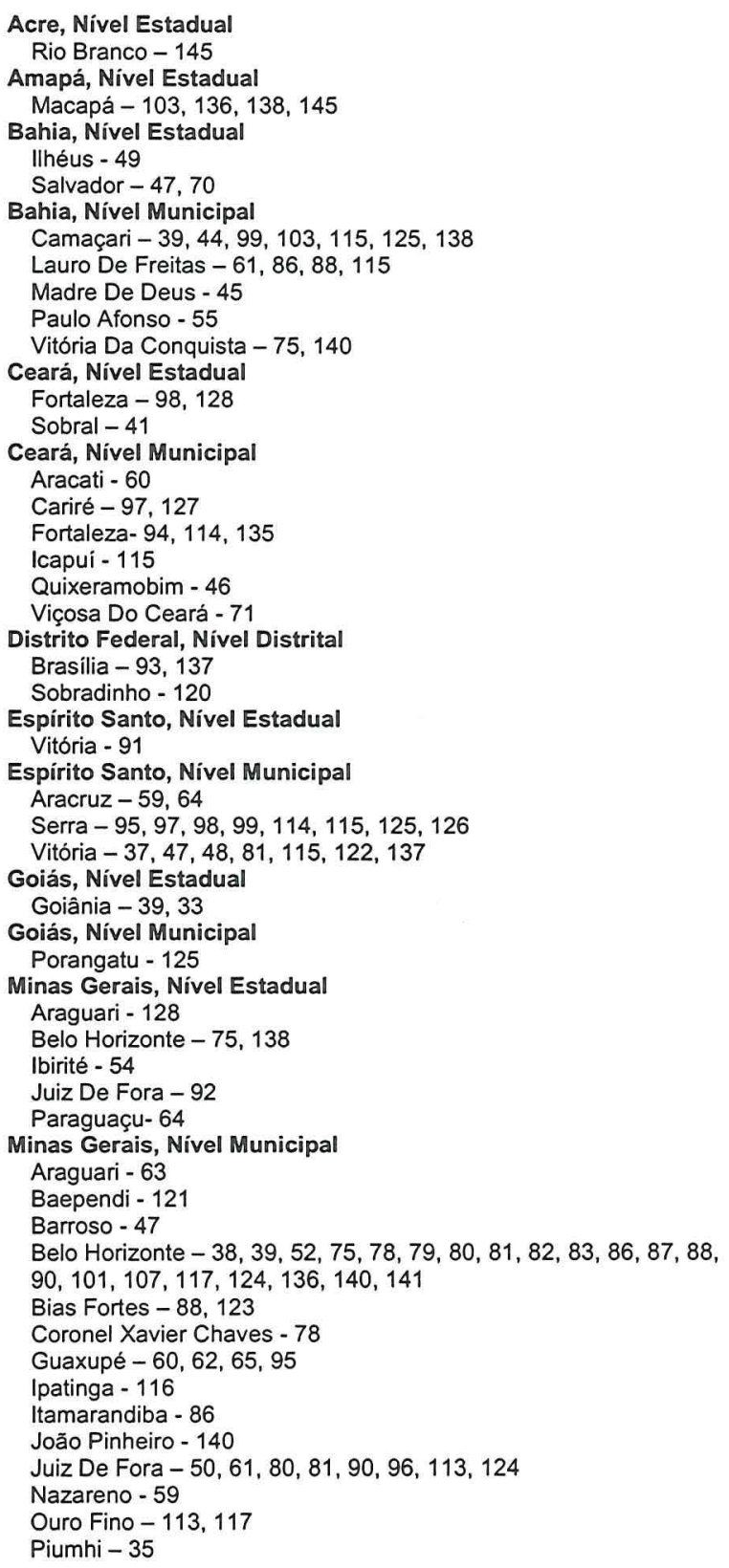


Ribeirão Das Neves - 66

Sacramento - 90

Santa Luzia - 53

São João Nepomuceno - 41

São Vicente De Minas - 35

Turmalina - 110

Maranhãi, Nivel Municipal

São Luis - 37, 143

Mato Grosso do Sul, Nivel Estadual

Campo Grande - 33, 34, 42, 139

Mato Grosso do Sul, Nivel Municipal Campo Grande - 101

Dourados - 36

Três Lagoas - 94, 95

Pará, Nível Estadual

Belém - 78, 109, 131

Pará, Nivel Municipal

Belém - 59, 114, 127

Rondon do Pará - 89

Paraiba, Nivel Estadual

João Pessoa - 134

Paraiba, Nivel Municipal

Campina Grande - 56, 62, 84, 89

Monteiro - 76

Pedras De Fogo - 72, 110

Prata $-54,145$

Sousa - 94

Pernambuco, Nivel Estadual

Recife - 117

Pernambuco, Nivel Municipal

Cabo De Santo Agostinho - 92

Camaragibe - 36, 45, 120, 121

Nazaré Da Mata

Petrolina - 75, 115, 116

Recife

Rio Formoso - 108

Piaui, Nivel Estadual

Teresina - 44, 114

Piaui, Nivel Municipal

Teresina - 103, 104, 123

Paraná, Nivel Estadual

Apucarana - 70

Curitiba -52

Londrina $-77,133$

Maringá - 109, 122

Paraná, Nível Municipal

Barracão - 134

Campo Mourão - 34, 46, 120, 129

Capanema - 73

Curitiba $-33,36,38,40,43,45,46,48,71,106,137$

Farol $-68,76,85$

Foz Do Iguaçu - 125

Guarapuava - 47, 140

Mandaguari - 106, 127

Matinhos - 49, 61

Nova Aliança Do Ivai - 62

Paranavai - 65, 80, 92, 94, 97, 106, 118, 133, 139

Perobal - 80

Telêmaco Borba - 49

Tupãssi $-51,69$

Umuarama - 83

Rio de Janeiro, Nível Estadual

Rio de Janeiro - 36, 134

Rio de Janeiro, Nível Municipal

Angra Dos Reis - 38, 54, 58

Armação Dos Búzios - 38

Barra Do Pirai - 77

Campos Dos Goytacazes - 99

Itaguai - 56, 67, 68

Parati - 74

Pirai - 136

Quissamã - 110

Rio Das Flores - 107

Rio das Ostras - 34

Rio De Janeiro - 34, 65, 80, 87, 89, 128

Volta Redonda - 35, 40, 75, 109, 110, 131, 136

Rio Grande do Sul, Nivel Estadual

Porto Alegre - 35, 43, 80, 91, 103, 121, 135, 142

Rio Grande do Sul, Nivel Municipal

Alto Feliz - 65, 109
Bento Gonçalves

Caxias Do Sul $-34,42,97$

Esteio - 134, 141

Frederico Westphalen - 106

Imbé - 51

Marau

Montenegro - 51

Novo Hamburgo - 33

Porto Alegre $-33,38,41,42,43,48,49,54,60,61,74,81,85,87$,

$88,94,97,98$

Rio Pardo - 123

Rolante - 83

Santa Bárbara Do Sul - 56, 58, 73, 84, 112

Santa Cruz Do Sul - 81

Sapucaia Do Sul - 78

Sobradinho - 120, 137

Três Passos - 108, 136

Viamão - 63, 66, 67

Santa Catarina, Nivel Estadual

Guarujá do Sul - 41

Santa Catarina, Nivel Municipal

Balneário Camboriú - 60

Blumenau - 45, 69, 93, 115, 117, 124, 125, 129, 139

Canoinhas - 56, 57, 84, 123

Chapecó - 47, 88, 102, 111, 112, 135, 136

Concórdia - 50

Dionísio Cerqueira - 49

Jaraguá Do Sul $-69,79,84,85,91,134$

Joinville $-48,52,53,55,56,64,66,67,69,72,86,107,108$

Lages - 93, 104, 105

Luzerna - 134

Otacilio Costa - 113

Palmeira - 117

São João Batista - 48

Seara - 95

São Paulo, Nivel Estadua

Bariri - 108

Bauru - 91, 92

Birigüi - 130, 132

Lins $-39,61,71,89,100,101,140,141$

Marília - 68, 92

Piracicaba - 34, 141

Pirassununga - 64

Presidente Venceslau - 121

Ribeirão Preto - 71

Rio Claro - 129

São Paulo - 33, 34, 35, 40, 45, 53, 64, 70, 71, 75, 77, 79, 82, 90

$103,107,116,121,129,130,131,139,143$

Suzano - 70

São Paulo, Nivel Municipal

Americana - 37

Agudos - 142

Américo Brasiliense - 133

Araraquara - 78,89

Araras $-48,124$

Bananal - 76

Barra Bonita - 130

Barretos - 118

Barueri - 87, 119, 122

Bauru - 77, 91, 92

Bertioga - 138

Birigüi - 130, 132

Campinas - 79, 93

Capão Bonito - 72, 116

Cerquilho - 91

Franca $-67,87,119$

Ilha Comprida - 137

Indaiatuba - 105

Itanhaém - 76, 104, 127. 130

Itapecerica Da Serra -128

Itatiba - 70

Itu -118

Jaboticabal -77

Limeira - 38

Lins - 39, 141, 143

Marilia - 118

Mirassol - 116

Motuca - 116

Narandiba - 104

Penápolis - 37, 41, 51 
Piracaia - 92

Piracicaba - 121

Pirapora Do Bom Jesus - 121

Potirendaba - 128

Praia Grande $-47,143$

Presidente Prudente - 118, 119

Ribeirão Pires - 69, 103, 122, 130, 138

Sales Oliveira - 106

Santo André - 33, 36, 37, 43, 52, 64, 65, 83, 99, 117 , $127,136,139$

Santos - 67, 119, 125, 126, 131

São Bernardo Do Campo - 44, 62, 63, 74, 86, 94, 96, $108,112,123,127,137$

São Caetano Do Sul - 66

São José Do Rio Preto - 112, 138

São José Dos Campos - 42, 53, 82, 105, 106, 130

São Paulo - 79, 82, 89, 98, 129

Sumaré - 141

Suzano - 70

Tarumā $-65,100$

Vinhedo -47

Sergipe, Nivel Estadual

Aracajú - 74

Sergipe, Nivel Municipal

Lagarto - 72, 100

Macambira - 100

Moita Bonita - 77

Pirambu, 101

Tocantins, Nivel Estadual

Palmas - 66

Tocantins, Nivel Municipal

Araguacema - 63, 128

Esperantina - 123

Palmas - 106

\section{MUNICÍPIOS OU ESTADOS E NIVVEL DE GOVERNO OU ÂMBITO SEGUNDO OS NOMES DOS PROGRAMAS INSCRITOS}

Agudos, SP, Nivel Municipal

Projeto Lixo que não é lixo e Meio Ambiente - 142

Alto Feliz, RS, Nivel Municipal

Apoio Sócio-Educativo Em Meio Aberto - 109

Grupo De Convivência De Pessoas Portadoras De

Deficiências - 109

Americana,, SP, Nivel Municipal

Projeto Semana da Água - 37

Américo Brasiliense, SP, Nivel Municipal

A Educação Com O Uso De Tecnologias - 133

Angra Dos Reis, RJ, Nivel Municipal

A Linguagem Da Informática: O Futuro É Agora $\mathrm{Na}$

Escola - 54

Formação De Voluntários Com Especialização Na Ilha

Grande - 38

Projeto A Pré-Escola: Tecendo Um Projeto De

Educação Infantil - 54

Projeto De Educação De Cegos E Visão Subnormal -

54

Projeto Movimento De Alfabetização De Jovens $E$

Adultos - 58

Apucarana, PR, Nivel Estadual

Doação De Sangue E Cidadania - 70

Aracajú, SE, Nivel Municipal

Projeto Previna-Se Menina, Previna-Se Mulher - 74

Aracati, CE, Nivel Municipla

Projeto Zumbi de Desenvolvimento das Atividades 60

Aracruz, ES, Nivel Municipal

Projeto De Educaçāo Indigena Tupinikim E Guarani 59

Projeto Implantação Do Bloco Único Nas $3^{a} S$ E $4^{\text {aS }}$

Séries - 64

Araguacema, TO, Nivel Municipal

Desenvolvimento Econômico Através Do Turismo No

Rio Araguaia - 138
Araguari, MG, Nivel Municipal

Centro De Convivência - 128

Araguari, MG, Nivel Estadual

Projeto De Educação Ambiental "Gira Sol" - 63

Araraquara, SP, Nivel Municipal

Programa De Atendimento Integral A Saúde Do Adolescente - Paisa

Saúde $\mathrm{Na}$ Bola - Saúde $\mathrm{Na}$ Escola - Escolinhas De Esportes - 89

Araras, SP, Nivel Municipal

Centro De Convivência Do Idoso Jesus De Nazaré - 124

Projeto Margem Verde - 48

Armação Dos Búzios, RJ, Nivel Municipal

Programa Governo Itinerante - 38

Baependi, MG, Nivel Municipal

Ocupar Para Educar - 121

Balneário Camboriú, SC, Nivel Municipal

Projeto Oficinas - 60

Bananal, SP, Nivel Municipal

Açōes De Controle Da Esquistossomose Mansônica - 76

Bariri, SP, Nivel Estadual

Banda Marcial Alexandre Giuliano Gallo - 108

Barra Bonita, SP, Nivel Municipal

Prevenção As Deficiências e Sociedade Inclusiva - 129

Barra Do Piraí, RJ, Nivel Municipal

Projeto De Residência Terapêutica Do Programa De Saúde Mental 77

Projeto De Gestão De Bovinocultura De Leite

Barretos, SP, Nivel Municipal

Projeto Barracão De Integração - 118

Barroso, MG, Nivel Municipal

Projeto "Barroso Joga Limpo"

Barueri, SP, Nivel Municipa

Programa Autoridades Mirins - 122

Programa De Embelezamento Urbano De Barueri - 87

Programa De Prestação De Serviços À Comunidade - 119

Programa Ouvidoria Geral Da Criaça - 122

Projeto Asas: Ler Também Liberta - 132

Bauru, SP, Nivel Municipal

Projeto Crescer - 77

Bauru, SP, Nivel Estadual

Programa De Direção Defensiva No Trânsito - 92

Programa Educacional - 91

Programa Jovens Contra O Crime - 91

Belém, PA, Nivel Municipal

Atendimento A Mulher - Albergue Emanuelle Rendeiro Diniz - 127

Educação Social De Rua - 114

Escola Circo: Uma Proposta Artístico Educativa - 113

Fundo Municipal De Geração De Emprego E Renda Ver-o-Sol - 140

Programa Bolsa Familiar Para A Educação - 59

Programa Familia Saudável - 73

Projeto Cores De Belém - 59

Projeto Cultura, Escola E Alegria - 59

Projeto Espelho: Reflexo Das Diversidades - 59

Projeto Mala Do Livro - 59

Projeto Sementes Do Amanhã - 113

Rede Criança Belém - 114

Belém, PA, Nivel Estadual

Comunidade Sócio Educativa / Escola Da Família - 109

Mãe Cơruja - 76

Programa De Apoio Ao Aleitamento Materno Exclusivo - PRAME 78

Programa Raizes - 131

Belo Horizonte, MG, Nivel Municipal

A Arte E O Lúdico Na Mobilização Social - 38

A Rede Pela Paz - 61

Alfabetização De Idosos - 124

Biblioteca Comunitária Santa Rita De Cássia - 83

Cadastramento Escolar De Belo Horizonte - 52

Casa Transitória - 126

Centro Cultural São Bernardo - 86

Centro De Educação Infantil - 69

Disque Idoso - 124

Grupo De Apoio Psicológico Ao Idoso - GAPSI - 124

Hospital-Dia: Qualidade E Eficiência No Sus - BH - 79

Lavadores De Carro Atuantes Em Vias Públicas - 140

O Passo Da Escola No Compasso Da Vida - 52

Profissionalização Do Pesquisador Assprom - 141

Programa BH Vida - 80

Programa Bolsa-Escola - 61

Centro De Vivência Agroecológica - CEVAE - 136

Programa Criança E Adolescente - 88 
Programa De Assistência Materna, Peri E Neonatal 75

Programa De Educação Patrimonial - 87

Programa De Formação E Qualificação Em

Informática Pública - 39

Programa De Geração De Trabalho, Renda E

Profissionalização - 142

Conjuntos Habitacionais E Lotes Urbanizados - AutoGestão - 81

Programa Direto Da Roça - 101

Preparação Profissional Para Adolescentes De Baixa

Renda - 107

Programa Superar - 90

Programa Vida Ativa - 90

Projeto De Reeducação Alimentar, Emagrecimento $E$ Qualidade - 79

Projeto Ecofios - 141

Projeto Menino No Parque - 117

Projeto Muriki - 128

Restaurante Popular De Belo Horizonte - 101

Transporte Coletivo Por Microônibus Em Vilas E

Favelas - 82

Belo Horizonte, MG. Nivel Estadual

Desenvolvimento Sustentável $\mathrm{Na}$ Bacia Do Rio

Aiuruoca - 138

Programa IPSEMG - Familia - 75

Bento Gonçalves, RS, Nivel Municipal

Programa Centros De Atendimento À Criança E Ao Adolescente - 110

Bertioga, SP, Nivel Municipal

Projeto Bertioga Município Saudável - 138

Bias Fortes, MG, Nivel Municipal

Escolinha De Futebol X Ação Social Com Os Jovens 88

Valorizando A Vida - 123

Birigüi, SP, Nivel Municipal

Creche Berçário Municipal Crianças Em Tratamento Especial - 130

Birigüi, SP, Nivel Estadual

Projeto Cidadania No Cárcere - 132

Blumenau, SC, Nivel Municipal

Abrigo Nossa Casa - 117

Capacitação Para Produção Em Hortas Associativas 139

Educação Ambiental No Museu De Ecologia Fritz

Müller - 65

Fórum De Defesa Das Pessoas Vitimas De Violência

Intra Familiar - 93

Fórum De Integração Portadores De Necessidades

Especiais - 129

Plano De Enchente - 45

Programa De Atenção E Proteção À População De/Na

Rua E Migrantes - 93

Programa De Garantia De Renda Familiar Mínima PGRFM - 93

Programa De Proteção A Infância E A Adolescência -

115

Projeto Alinhavando Cidadania - 126

Programas Para Execução Das Medidas Sócio-

Educativas - 114

Serviço Atenção Ả Familia - 93

Tecendo Saber Nas Questōes Da Terceira Idade - 124

Brasilia, DF, Nivel Distrital

Projeto De Execução Da Medida Sócio-Educativa De

Semiliberdade - 93

Promoção Do Desenvolvimento Econômico Integrado $-137$

Brasilia, DF, Nivel Estadual

Projeto Brincando E Educando - 120

Cabo De Santo Agostinho, PE, Nivel Municipal

Programa Seguranca Amiga - 92

Cáceres, MT, Nivel Municipal

Saúde, Teatro, Educação - 66

Cacoal, RO, Nivel Municipal

Diagnóstico Agroambiental Participativo Paiter - 135

Camaçari, BA, Nivel Municipal

Bolsa De Complementação Educacional - 115

Camaçari Verde - 44

Casamento Coletivo - 103

Programa De Educação Continuada - PEC - 39
Programa De Renda Minima Familiar De Promoção Sócio

Educativa - 99

Projeto Aldeia Hippie - Arembepe - 138

Projeto Idoso $\mathrm{Na}$ Praça - 125

Camaragibe, PE, Nivel Municipal

Plano De Defesa Civil De Camaragibe - 45

Programa De Atendimento A Criança E Ao Adolescente - PACA -

121

Programa De Atendimento A Mulher - PAM - 127

Projeto Brigada Ecológica - 120

Projeto Criança Camará - 120

Projeto Meninos E Meninas De Camaragibe - 120

Sistema Alternativo De Comunicação - 36

Campina Grande, PB, Nivel Municipal

Creche Campina - 56

Mexe Campina - 89

Pintando $2000-84$

Programa Arte $\mathrm{Na}$ Comunidade - 84

Programa Integrado: Cidadania $\mathrm{Na}$ Escola - 62

Campinas, SP, Nivel Municipal

Serviço Alternativo De Proteção Especial A Criança E Ao

Adolescente - SAPECA - 93

Sistema De Atendimento Domiciliar - 79

Campo Grande, MS, Nivel Estadual

Instituição Comunitária De Crédito Banco Do Povo - MS - 139

Ms 2020 - 33

Programa De Eletrificação Rural Luz No Campo - 42

Projeto De Capacitação Continuada E Assessoria Aos Municipios 34

Campo Grande, MS, Nivel Municipal

Central De Processamento De Alimentos - 95

Preparação De Adolescentes Das Camadas - 139

Projeto Mais - Mais Que A Universidade, Ação Com A Comunidade $-101$

Campo Mourão, PR, Nivel Municipal

A Escola Um Espaço Informatizado - 129

Programa Municipal De Descentralização De Recursos E Decisões

$-34$

Qualidade Do Ambiente Produtivo Rural - 46

Rede De Amigos - 120

Campos Dos Goytacazes, RJ, Nivel Municipal

Monitoramento E Avaliação: Programa Participativo De Gestão - 99

Sistema Informatizado De Atendimento - SAI - 99

Canoinhas, SC, Nivel Municipal

Horta Escolar - 56

Programas Sócio Educativos

Qualidade Ambiental É A Meta - 57

Resgate Histórico Cultural - 84

Capanema, PR, Nivel Municipal

Mutirăo Da Saúde - 73

Capão Bonito, SP, Nivel Municipal

Cidadão Participativo E Presente - 116

Projeto Ciranda - Oficinas Terapêuticas - 72

Projeto Da Gestante Dona Malvina Do Amaral - 73

Caraguatatuba, SP, Nivel Municipal

Projeto Cinema Nos Bairros - 87

Cariré, CE, Nivel Municipal

Programa De Combate A Desnutrição Infantil - 97

Doce Mãe - 127

Caxias Do Sul, RS, Nivel Municipal

Associação De Recicladores - 97

Projeto Zona Azul - 42

Reforma Do Estado E Da Seguridade Municipal - 34

Cerquilho, SP, Nivel Municipal

Projeto Vivendo E Aprendendo - 101

Chapecó, SC, Nível Municipal

Feiras Agroecológicas De Chapecó - 102

Gestão Do Lixo Urbano De Chapecó - 47

Planejamento Estratégico Participativo Do Meio Rural - 136

Programa Criança Legal - 88

Programa Sócio Educativo Semente De Cidadania - 111

Programa Sócio-Educativo Crescendo E Aprendendo - 112

Programa Sócio-Educativo Recanto Da Criança E Adolescente 111

Sócio-Educativo Posto Do Pequeno Lavador - 111

Concórdia, SC, Nivel Municipal

Banco De Sementes De Espécies Nativas - 50

Coronel Xavier Chaves, MG, Nivel Municipal

Saúde Bucal No Município De Coronel Xavier Chaves - 78

Curitiba, PR, Nivel Municipal 
Licenciamento Ambiental Municipal - 46

Lixo Que Não É Lixo - 48

Modelo Colaborativo - 137

Plano De Avaliação Sanitária Dos Estabelecimentos

De Saúde - 36

Programa De Incentivo A Qualidade - 40

Programa Mãe Curitibana - 71

Programa Olho D'água - 38

Responsabilidade Das Empresas de Serviço Público

Terceirizado - 45

Rua Da Cidadania - 33

Sistema De Monitoramento De Áreas Verdes - 49

Sistema De Monitoramento Georeferenciado - 36

Sistema De Unidades De Conservação Do Município

De Curitiba - 43

Curitiba, PR, Nivel Estadual

Usina de Conhecimento: Conhecer para Transformar 52

Currais Novos, RN, Nivel Municipal

Programa De Apoio A Pessoa Idosa Em Regime

Aberto - 126

Projeto De Iniciação Ao Atletismo - 88

Diadema, SP, Nivel Municipal

Projeto Cia. Experimental Mu...Dança - 78

Dionísio Cerqueira, SC, Nivel Municipal

Amigos Da Natureza - 49

Dourados, MS, Nivel Municipal

Projeto De Incremento De Arrecadação Do ISSQN -

36

Esperantina, TO, Nivel Municipal

Programa Pioneiros Mirins - 123

Esteio, RS, Nivel Municipal

Programa De Incentivo Ao Comércio Local - 134

Programa De Incentivo Ao Emprego - 141

Farol, PR, Nivel Municipal

Programa Aprendiz - Inicialização E Qualificação

Profissional - 68

Programa Momento Pedagógico Entre Pais E Filhos 67

Programa Pró-Vida - 76

Programa Visita Saudável - 71

Saúde Bucal - Gente Miúda - 76

Feira De Santana, BA, Nivel Municipal

Associativismo Rural E Urbano - 137

Fortaleza, CE, Nivel Municipal

Centro De Assistência À Criança E A Familia - 111

Formação Social Para As Famílias - 94

Núcleo De Atendimento Psicológico Sistêmico -

NUAPSI - 114

Núcleo De Prevenção Ao Uso Indevido De Drogas NUPRED - 114

Programa De Prática Profissional Em Informática -

141

Projeto Crescer Com Arte - 111

Projeto Familia Cidadã - 110

Projeto Semear - 111

Projeto Vivamar - 135

República Da Criança Da Cidade - 111

Fortaleza, CE, Nivel Estadual

Casa Da Juventude - 98

Casa Do Menino Trabalhador - 98

Mulheres Empreendedoras - 128

Núcleo De Iniciação Ao Trabalho Educativo E

Capacitação - 100

Restaurante - Escola Um, Dois, Feijão Com Arroz 112

Foz Do Iguaçu, PR, Nivel Municipal

Programa De Apoio A Pessoa Idosa - 125

Franca, SP, Nivel Municipal

Café Com Música - 87

Caminhando Rumo A Alfabetização Musical - 67

Escola Municipal De Iniciação Musical - Emim - 119

Folia No Parque - 119

Frederico Westphalen, RS, Nivel Municipal

Associação De Vilas: É Preciso Repartir O Meu Viver Com Todos - 106

Goiânia, GO, Nivel Estadual

Programa Casa Abrigo - 33

Programa De Qualidade Da Agência Ambiental - 39

Guarapuava, PR, Nivel Municipal
Programa Bairros Em Ação - Renda Mais - 140

Programa Nosso Lixo - 47

Guarujá Do Sul, SC, Nivel Estadual

Água Comunitária - 41

Guaxupé, MG, Nivel Municipal

Estufa Hidropônica - 60

Horto Florestal - Brasil Criança Cidadã - 95

Integração Escola/Familia - Seu Filho, Nosso Aluno - 60

Nucleação Rural - 62

Programa De Educação Pré-Escolar - 60

Viveiro De Mudas - Plantas Nativas - 65

Ibirité, MG, Nivel Municipal

Programa De Educação Em Tempo Integral - PETI - 54

Icapuí, CE, Nível Municipal

Programa Dia Feliz - 115

Ilha Comprida, SP, Nivel Municipal

Exploração Sustentável Da Samambaia Silvestre - 137

Ilhéus, BA, Nivel Estadual

Programa De Recuperação Da Bacia Do Rio Cachoeira - 49

Imbé, RS, Nivel Municipal

Centrais De Apoio Pedagógico Cap I E Cap II - 51

Escola Viva - 51

Oficinas Pedagógicas - 51

Indaiatuba, SP, Nivel Municipal

Centro De Recreação Infantil Comunitário - 105

Ipatinga, MG, Nivel Municipal

Projeto Vivendo E Aprendedo Família - 116

Itaguai, RJ, Nivel Municipal

Projeto Educação De Trânsito - 58

Projeto "Alimentação Alternativa" - 56

Projeto Final De Semana Do Escolar - 57

Projeto Prefeito Mirim - 57

Projeto Natação Mãos A Obra - 57

Projeto Educação Ambiental - 57

Projeto "Educação De Jovens E Adultos" - 57

Projeto Horta Escolar - 57

Projeto Educação Sexual - 58

Projeto Drogas - 58

Itamarandiba, MG, Nivel Municipal

Preservação Do Patrimômio Cultural De Itamarandiba

Itanhaém, SP, Nivel Municipal

Casa Da Mulher - 127

Flores Da Mata - 104

Projeto Amigo - 76

Produção De Alimentos Ita Sabor - 130

Itapecerica Da Serra, SP, Nivel Municipal

Inclusão Do Portador De Necessidades - 128

Itatiba, SP, Nivel Municipal

Programa De Assistência E Internação Domiciliária - 70

Itu, SP, Nivel Municipal

Centro De Atendimento A Criança E Ao Adolescente - 118

Programa Liberdade Assistida - 118

Jaboticabal, SP, Nivel Municipal

Programa Útero - 77

Jaraguá Do Sul, SC, Nivel Municipal

Canto Do Conto - 84

Caravana Da Alegria - 85

Concurso De Declamação - 85

Empresa-Tur - 134

Festival Estudantil Da Canção - 85

Integração Do Teatro Estudantil De Jaraguá Do Sul - 84

Jaraguá Em Dança - 85

O Sonhador - 84

Pm-Tur - 91

Projeto Música Na Praça - 85

Sistema De Informação Da Hotelaria - SIVHO - 134

Ji Paraná, RO, Nivel Municipal

Ação Para O Desenvolvimento Sócio Cultural E Econômico - 13

João Pessoa, PB, Nivel Municipal

Centro Livre Meninada - Unidade Do Projeto Meninada - 110

João Pessoa, PB, Nivel Estadual

Programa De Apoio A Piscicultura - 134

João Pinheiro, MG, Nivel Municipal

Programa De Emprego E Renda - Proder - 140

Joinville, SC, Nivel Municipal

Clubes Agricolas Escolares - 56

Corte Costura Industrial - 52

Desenho Mecânico - 52

Educação Profissional - 55

Eletricista Instalador - 53 
Informática Nos Bairros - 52

Joinville - Ação Verão 2000 - 86

Marcenaria - 52

Mecânica Geral - 64

Mutirão Da Alfabetização - 66

Programa De Distribuição De Carnes Ao Comércio

Varejista - 72

Programa De Orientação E Apoio Sócio-Familiar

Medidas De Proteção - 108

Programa Escola Período Integral - Área Rural - 55

Programa Jovem Cidadão - 107

Programa Prevenção, Educação E Vida - Previda - 55

Projeto Valores E Atitudes - 48

Na Busca Da Melhoria Do Meio Ambiente E Da

Qualidade De Vida

Técnicas Artesanais - 69

Turismo Infantil, Esse E Nota Mil - 67

Juiz De Fora, MG, Nivel Municipal

A Caminho Da Inclusão

Alfabetização De Idosos - 124

Avaliação Nutricional De Crianças Das Creches

Municipais - 96

Casa Do Aconchego - 96

Dança Sênior - 124

Projeto Casa Do Pequeno Jardineiro - 113

Mutirão De Saúde - 80

Núcleo De Convivência Para A População De Rua -

Política De Abrigo - Cooperação Técnico-Financeira A Abrigos - 113

Programa Rede Cidadã - 96

Projeto Festival Esportivo Das Escolas Municipais De

Dança-Educação - Femde

Projeto Lotes Verdes

Projeto Nadar

Projeto Sócio-Educativo - 113

Revitalização Estética De Habitações Populares - 81

Juiz De Fora, MG, Nivel Estadual

Posto Itinerante De Atendimento Ao Cidadãolagarto, SE - 92

Lagarto, SE, Nivel Municipal

Programa de Assistência à Saúde às Comunidades

Carentes - 79

Projeto Educar par Sorrir - 72

Lages, SC, Nivel Municipal

Programa de orientação e Apoio Sócio Familiar - 93

Lauro De Freitas, BA, Nivel Municipal

Programa Cadete Mirim

Programa Esporte Cidadão - 88

Programa Saúde Da Familia E Agentes Comunitários

De Saúde - 70

Programa Valores Da Terra - 86

Projeto De Alfabetização De Jovens E Adultos Com

Aceleração

Projeto Essa É Nossa Praia - 89

Limeira, SP, Nivel Municipal

Programa Limeira Saudável - 38

Lins, SP, Nivel Municipal

Caravana Da Cidadania - 39

Contrato Coletivo De Trabalho

Orçamento Participativo - 39

Programa Garantia De Renda Minima Familiar

Programa Primeiro Emprego

Projeto A Escola No Trabalho

Projeto Crescer No Esporte - 89

Projeto Renascer

Zona Azul - Cemic

Lins, SP, Nivel Estadual

Núcleo De Reabilitação Neurológica Infanto Juvenil 71

Londrina, PR, Nivel Municipal

Agricultores-Pesquisadores

Uni Londrina - Educação Dos Profissionais De Saúde $-77$

Luzerna, SC, Nivel Municipal

Expressão Agropecuária - Incentivo A Emissão De

Nota Fiscal De Produtor - 134

Macambira, SE, Nivel Municipal

Projeto "Espirito Jovem" - 100

Macapá, AP, Nivel Estadual
Programa Cooperamaria - 138

Programa Castanha - 136

Programa Família Cidadã - 103

Projeto Pirralho - 145

Maceió, AL, Nivel Municipal

Cidadão Expoart - 142

Madre De Deus, BA, Nivel Municipal

Programa De Exelência Em Gestão Ambiental E Segurança - 45

Manaus, AM, Nivel Municipal

Cidadão Cliente - 54

Mandaguari, PR, Nivel Municipal

Programa Escola Da Gestante - 127

Escola Do Trabalho - 106

Marau, RS, Nivel Municipal

Projeto Aprendendo A Construir - Programa AABB-Comunidade 118

Marilia, SP, Nivel Municipal

Projeto Casa Do Pequeno Cidadão - 118

Marilia, SP, Nivel Estadual

Ação Policial - 68

Ensino - Aprendizagem Em Medicina E Enfermagem - 68

Maringá, PR, Nivel Estadual

Banco De Dados Bibliográfico, Institucional E De Periódicos - 122

Projeto Crianças E Adolescentes Nas Ruas - 109

Projeto Educação Para Cidadania - 122

Matinhos, PR, Nivel Municipal

Municipalização Da Unidade De Conservação - Parque Florestal -

Programa Água Limpa - 61

Mirassol, SP, Nivel Municipal

Projeto Girassol - Infância E Cidadania - 116

Monteiro, PB, Nivel Municipal

Consórcio Intermunicipal De Saúde - 76

Montenegro, RS, Nivel Municipal

Ação Comunitária Fundarte - 51

Projeto Dançar - 51

Mossoró, RN, Nivel Municipal

Água Viva

Luz Do Sol - 42

Motuca, SP, Nivel Municipal

Projeto Eu No Sitio - 116

Narandiba, SP, Nivel Municipal

Projeto Pró-Criança - 104

Nazaré Da Mata, PE, Nivel Municipal

Projeto Parto Legal - 99

Nazareno, MG, Nivel Municipal

Programa Nazareno Verde - 59

Nova Aliança Do Ivai, PR, Nivel Municipal

llumine Essa Idéia - 62

Novo Hamburgo, RS, Nivel Municipal

Gestão Ambiental Municipal - 33

Otacilio Costa, SC , Nivel Municipal

Abrigo De Criança E Adolescente - 113

Ouro Fino, MG, Nível Municipal

Cursos Municipais Profissionalizantes - 64

Inglês Nas Escolas Rurais Municipais - 117

Projeto Núcleo De Atendimento Á Infância E Adolescência - 113

Vida Saudável - 117

Palmas, TO, Nivel Estadual

Projeto Amigos Do Meio Ambiente - 106

Palmas, TO, Nivel Municipal

Programa Escola Autônoma De Gestão Compartilhada - 66

Palmeira, SC, Nivel Municipal

Escolinha De Futebol Para Crianças E Adolescentes - 117

Pão De Açucar, AL, Nivel Municipa

Fundo Para O Desenvolvimento Da Agricultura Familiar - 140

Paraguaçu, MG, Nivel Estadual

Projeto Fazenda Escola Fundamar - 64

Paranavai, Pr, Nivel Municipal

Amor Exigente - Grupo Renascer - 65

Centro De Educação Do Menor Integrado A Comunidade - Cemic -

94

Estação Do Ofício - 133

Programa Municipal De Apoio, Orientação E Promoção A Familia 92

Programa Paranavai Sempre Sorrindo

Programa Trabalhart - 139

Projeto "Restaurante Italianinho Expresso" - 139

Projeto Agente Jovem De Desenvolvimento Social Humano - 118

Projeto Formando Cidadão - 106 
Atendimento Psicopedagógico Específico Com

Adolescentes - 99

Projeto Suco Justo - 97

Parati, RJ, Nivel Municipal

Programa De Saúde Mental De Paraty - Trajeto Para A Cidadania - 74

Paulo Afonso, BA, Nivel Municipal

Pólos De Estudo - Formação Continuada Do

Educador - 55

Programa De Alimentação Escolar Do Município De

Paulo Afonso - 55

Pedras De Fogo, PB, Nivel Municipal

Atividade De Implementação Do Sistema De

Informações Sobre Nascidos Vivos - 72

Autópsia Verbal: Investigação De Óbito De Menores

De 01 Ano - 72

Programa Saúde Bucal Do Escolar - 76

Programa Saúde Intersetorializada - 72

Projeto "Curumim Do Futuro" - 110

Projeto Cidadão Do Futuro - 72

Projeto Taipa Nunca Mais - 81

Penápolis, SP, Nivel Municipal

Centro De Educação Ambiental - 51

Limpeza De Caixa D'água E Controle De Vetores - 41

Manutenção Preventiva E Corretiva De Hidrômetros 41

Participação Popular Nas Ações Do Departamento 37

Perobal, Nivel Municipal

Moradia Digna Para Todos - 80

Quando A Escola Está Para A Criança, A Criança

Está Na Escola - 55

Petrolina, PE, Nível Municipal

Programa Banco De Leite - 75

Programa Da Feliz Idade - 125

Programa De Erradicação Do Trabalho Infantil - Peti -

115

Programa Esporte E Cultura Dos Meninos De Todos

Nós - 116

Programa Mãe Canguru - 75

Piracaia, SP

Programa Sócio Ambiental Selo Cidadania - 92

Piracicaba, SP, Nivel Municipal

Projeto Cidadania Nos Bairros Através Da

Brinquedoteca - 121

Piracicaba, SP, Nivel Estadual

Assessoria Técnica E Organizacional A Produtores

Familiares No - 135

Projeto Banana - Artesanato - 141

Sistema De Gestão Da Divisão De Biblioteca E

Documentação - 34

Pirai, RJ, Nivel Municipal

Programa De Desenvolvimento Local De Pirai - 136

Pirambu, SE, Nivel Municipal

Pirambu Solidário - 101

Pirapora Do Bom Jesus, SP, Nivel Municipal

Patrulha Mirim De Pirapora - 121

Pirassununga, SP, Nivel Estadual

Dr. Escargot: Utilização De Pequenas Criações $\mathrm{Na}$ Terapia - 64

Piumhi, MG, Nivel Municipal

Projeto Curumim - 35

Porangatu, GO, Nivel Municipal

Programa De Apoio À Pessoa Idosa - 125

Porto Alegre, RS, Nivel Municipal

Assessoria De Descentralização - 85

Central De Regulação E Internações Hospitalares - 74

Condomínio Residencial Lupicínio Rodrigues:

Programa De Regularização Fundiária

Conselhos De Praças E Parques - 38

Controle Das Emissões Eletromagnéticas Não-

Ionizantes - 43

Curta Nas Telas - 85

Destinação Ecológica Dos Resíduos De Poda Em

Porto Alegre - 44

Escola Municipal De Ensino Fundamental Porto

Alegre - 60

Incentivo A Participação Popular $\mathrm{Na}$ Luta Contra As

Dst/Aids - 74

Inclusão Ambiental E Educação Social - 121
Licenciamento Ambiental Em Porto Alegre - 44

Licenciamento Ambiental Para Redes De Infra-Estrutura Urbana -

44

Museu Itinerante Memória Carris - 54

Operação Ar Puro - 46

Planejamento E Orçamento Participativo Da Rede Municipal - 60

Plano De Manejo Participativo Na Reserva Do Lami - 49

Programa Adote Uma Praça - 44

Programa De Atendimento E Abrigagem A População Adulta -

Serviço De Abrigagem - Abrivivência

Programa De Abrigagem A Crianças E Adolescentes - 97

Serviço de Abrigagem Temporária a Crianças e Adolescentes - 98

Programa De Redução De Danos - 74

Programa De Regionalização E Participação - 33

Programa de Regularização Fundiária - 81

Programa Em Cada Campo Uma Escolinha 188

Programa Familia: Apoio E Proteção - 98

Programa Graxaim - 97

Programa S.O.S. Afastados - 94

Projeto Agenda Ambiental - 87

Projeto Arpão - 74

Projeto De Educação Para O Trabalho - 142

Projeto Reciclar - 142

Projeto Tratando A Água Conosco - 41

Semana Da Primavera - 61

Semana Do Meio Ambiente - 39

Simulação De Tráfego Em Porto Alegre - 42

Usina De Beneficiamento De Plásticos - 135

Porto Alegre, RS, Nivel Estadual

Iniciação A Pesquisa - 91

Manual Da Brigada - Guia De Serviços - 91

Melhora Na Qualidade De Vida Resulta Em Excelência Na Prest De

Serv. -91

Museus Do Rio Grande Do Sul - 83

Planejamento Participativo Regional - 35

Projeto Construindo A Cidadania Da Mulher - 103

Projeto Santa Marta - 81

Rio Grande Rural - 43

Potirendaba, SP, Nivel Municipal

Cidadão $2000-66$

Projeto Arbore-Vida - 128

Praia Grande, SP, Nivel Municipal

Ampliação Da Capacidade De Profissionais De U.B.S. Em Dst/Aids

$-143$

Festival De Jogos Cooperativos - 63

Programa Para Atendimento E Funcionamento De Creches - 67

Projeto De Educação Inclusiva - 63

Projeto Educador Social - 63

Projeto Evasão Escolar - 55

Projeto Qualidade De Vida

Prata, PB, Nivel Municipal

Justiça Cidadã - 145

Quantidade X Qualidade - 54

Presidente Prudente, SP, Nivel Municipal

Projeto Criança Cidadã - 118

Projeto Jovem Cidadão - 119

Presidente Venceslau, SP, Nivel Estadual

Programa Educacional De Resistência Às Drogas E A Violência 121

Quissamã, RJ, Nivel Municipal

Programa De Prevenção E Erradicação Do Trabalho Infantil - 110

Quixeramobim, CE, Nivel Municipal

Projeto Pingo D'água - 46

Recife, PE, Nivel Municipal

Jovem Pai - 116

Recife, PE, Nivel Municipal

Combate Aos Maus-Tratos Na Infância E Adolescência - 117

Ribeirão Das Neves, MG, Nível Municipal

Universalização Do Ensino Médio - 66

Ribeirão Pires, SP, Nivel Municipal

Atendimento Ao Portador De Deficiência Severa E Profunda - 69

Movimento De Alfabetização De Jovens E Adultos - 68

Programa De Segurança Alimentar: Reeducação Alimentar - 68

Projeto A Escola Vai Dançar - 122

Projeto Ação Integrada De Enfrentamento A Pobreza - 103

Projeto Bloco Na Rua - 68

Projeto De Educação Ambiental Muda O Mundo Raimundo

Projeto De Teatro Para Deficientes Auditivos

Requalificação Dos Trabalhadores Da Extração Mineral De Ribeirão

Pires - 138 
Ribeirão Preto, SP, Nivel Estadual

Programa De Nanismo Hipofisário - 71

Rio Branco, AC, Nivel Municipal

Justiça Volante - 145

Rio Claro, SP, Nivel Municipal

Tratamento Eletrolitico De Efluentes

Programa De Desenvolvimento Sustentável $\mathrm{Na}$ Apae

De Rio Claro - 129

Rio Claro, SP, Nivel Municipa

Programa Adolescente Consciente - 46

Rio Das Flores, RJ, Nível Municipal

Orçamento Participativo - 107

Rio Das Ostras, RJ, Nivel Municipal

Orçamento Participativo - 34

Rio De Janeiro, RJ, Nivel Municipal

Adolescência O Prazer Das Descobertas... Por Um

Mundo Melhor - 65

Associação Saúde Criança Renascer - 80

Oficina Do Surf - 89

Programa De Orientação Sexual - Educação

Ambiental E Saúde - 71

Projeto De Volta A Cidadania - 128

Projeto Familia Acolhedora - 109

Roda Certa - 87

Rio De Janeiro, RJ, Nivel Estadual Espaços Da Ciência - 133 Indice De Qualidade Dos Municipios - Projeto IQM 36

Jovens Talentos Para A Ciência - 133

Praça Da Ciência Itinerante - 133

Rio Formoso, PE, Nivel Municipal

Programa Ciranda Da Criança Celebrando O Estatuto $-108$

Rio Pardo, RS, Nivel Municipal

Atendimento Alternativo A Crianças E Adolescentes 123

Rolante, RS, Nivel Municipal

Festivale - Festival De Teatro Do Vale Do Paranhana 83

Rondon Do Pará, PA, Nível Municipal

Jogando E Aprendendo - 89

Sacramento, MG, Nivel Municipal

Aprendendo Com A Natureza: Pensar E Sentir - 104

Sales Oliveira, SP, Nivel Municipal

Projeto Educar "Brasil Criança Cidadã" - 106

Salvador, Ba, Nivel Estadual

Sac Saúde Móvel - 70

Programa De Coleta Seletiva De Lixo - Recicla Cab 47

Santa Luzia, MG, Nivel Municipal Geo-História - 88

Santo André, SP, Nivel Municipal

Advocacia Pública, Integrada E Cidadã Do Municipio

De Santo André - 127

Agência De Desenvolvimento Econômico Do Grande

$A B C-136$

Banco De Dados Georeferenciados De Acidentes De

Trânsito - 43

Bilhetagem Eletrônica No Sistema De Transporte

Público Municipal - 83

Central De Trabalho E Renda - 142

Gestão Integrada Da Área De Proteção De

Mananciais De Santo André - 33

Guia Fácil - 37

Movimento De Alfabetização Regional - Mova - 52

Ouvidoria Da Cidade De Santo André - 36

Politica Habitacional De Santo André

Programa Andrezinho Cidadão - 117

Programa Cidade Acessivel - 130

Programa De Atenção À População Adulta Em

Situação De Rua - 99

Programa De Segurança E Educação No Trânsito - 64

Projeto Alquimia - Programa De Qualificação E

Requalificação Profissiona

Projeto Cidade Futuro - Santo André 2020 - 38

Projeto Eixo Tamanduatehy - 43

Projeto Laboratórios Pedagógicos - 65

Santos, SP, Nivel Municipal

Defensoria Pública Na Área De Adolescente Em

Conflito Com A Lei - 119
Centro De Informação, Defesa E Orientação Ao Consumidor - 131

Educação De Valores: Cidadão Em Ação - 67

Espaço Meninas - 119

Medidas Sócio-Educativas Em Meio Aberto - 119

Programa Nossa Familia - 100

Projeto Casa Do Trem - Serua - 120

Projeto Educação Pelo Trabalho - 126

Projeto Praticagem - 125

Projeto República - Alternativa De Moradia Para A Pessoa Idosa 125

Projeto Vovô Sabe Tudo - 126

São Bernardo Do Campo, SP, Nivel Municipal

Bolsas De Estudos - 62

Bolsas E Auxilios - 62

Cult Circuito - 86

Fundação Criança De São Bernardo Do Campo - 123

Oficinas Culturais - 86

Prevenir Só Educando - 63

Programa Adolescer - 108

Programa Bairro Ecológico - 44

Assessoria E Apoio Técnico As Entidades Assistenciais - 94

Programa De Atenção A Criança Desnutrida - 112

Programa De Atenção A Mulher Em Situação De Violência -Pam

Programa De Atenção Ả Violência E Abuso Sexual - 74

Programa De Educação Do Adolescente Para O Trabalho - 108

Programa De Educação Tecnológica - 62

Programa De Inicio Á Ação Do Trabalho - 112

Projeto Redução Dos Recursos Naturais - Água - 62

Programa Lixo E Cidadania De São Bernardo Do Campo - 136

Programa Rede Escolar De Bibliotecas Interativas - Pró-Rebi - 63

Projeto Crescer - 96

Recuperação Urbana Ambiental - Jardim Detroit / Carminha - 44

Sons Da Cidade - 86

São Caetano Do Sul, SP, Nivel Municipal

Projeto Musicalização Infantil - 66

São Gabriel Da Cachoeira, AM, Nivel Municipal

Arte Baniwa - 135

São João Batista, SC, Nivel Municipal

Educação Para A Preservação Do Meio Ambiente - 48

São João Nepomuceno, MG, Nivel Municipal

Microestação De Tratamento De Esgotos Sanitários - 41

São José Do Rio Preto, SP, Nivel Municipal

Programa De Mini Distritos E Serviços - 138

Projeto Missão Resgate

São José Dos Campos, SP, Nivel Municipal

Casa Da Gente - 82

Complementação Em Alfabetização - 106

Conselho Infanto Juvenil - 105

Educação Inclusiva - 130

Grupo De Orientadores Ambientais - GOA - 105

Laboratório De Aprendizagem

Marronzinho-Mirim - Um Programa De Educação Para O Trânsito

Núcleo De Oficina Pedagócica "Eureka" - 53

Programa De Melhorias Viárias - 106

Projeto Adole-Ser - 105

Projeto Aquarela - 105

Projeto Maioridade - 105

Salas De Recursos - Removendo Barreiras A Aprendizagem - 53

São Luis, Ma

Consórcio Intermunicipal De Produção E Abastecimento - 37

Fazendamigos - 143

São Paulo, SP, Nivel Municipal

Construção De Moradia Popular Por Regime De Mutirão - 82

Oficinas Para A Melhor Idade - 89

Programa De Educação Ambiental Do Arrastão - 98

Programa De Inserção De Crianças Com Deficiência Na Rede De

Creches - 129

Projeto Saúde No Parque - 79

São Paulo, SP, Nivel Estadual

(Re)Construção Coletiva Das Rotinas De Interação Social - 40

A Questão Da Qualidade No Serviço Público - 77

Brinquedoteca Do Instituto Da Criança - 107

Café Da Manhã Com O Diretor - 143

Campanha Nacional Olho No Olho - 70

Comitê Juvenil Do Instituto Da Criança - 75

Contadores De Histórias Da Associação Viva E Deixe Viver - 107

Estação Especial Da Lapa - 129

Experiências Na Implantação De Sistema De Gestão De Custos 35

Gerenciamento De Substâncias Quimicas Perigosas - 45 
Habilitação Do $3^{\circ}$ Setor Como Operador Da Rede

Pública De Saúde - 33

Humanizar Brincando Com O Proces. Educ. $\mathrm{Na}$

Prática De Saúde - 107

Faculdade Em Casa - 40

Jovem Cidadão - Serviço Civil Voluntário - 103

Pintando O Sete - 116

Programa Comunidade Participativa - 82

Programa De Apoio À Pessoa Portadora De

Deficiência - 129

Programa De Atenção Primária Em Saúde Bucal - 70

Programa De Auto-Emprego - 139

Programa De Educação Ambiental Na Trilha - 58

Programa De Educação Ambiental $\mathrm{Na}$ Trilha - 64 Programa De Prevenção E Combate A Principio De Incêndio - 45

São Vicente De Minas, MG

Sistema Integrado De Saneamento Rural - 35

Sapucaia Do Sul, RS

Escolinhas Comunitárias Municipais De Sapucaia Do Sul - 78

Seara, SC

Programa Qualidade De Vida Na Familia - Geração De Renda - 95

Serra, ES

Programa Emergencial De Combate A Fome E Ao Desemprego - 95

Projeto Conviver/ Grupos De Idosos De Serra -- 126

Projeto De Plantão Na Sua Casa - 98

Projeto Esporte Cidadão - 115

Projeto Hemodiálise E Diálise - 99

Projeto Mãos À Terra - 114

Projeto Serra Cidadã - 97

Projeto Yoga Para Terceira Idade - 125

Sobradinho, DF, Nivel Distrital

Projeto Cidadania Ativa - 120

Sobradinho, RS, Nivel Municipal

Plano Piloto De Agricultura Ecológica Da Região Centro-Serra - 137

Sobral, CE, Nivel Municipal

Sistema Integrado De Saneamento Rural - Sisar

Sousa, PB, Nivel Municipal

Programa "Pão E Leite Na Mesa" - 94

Casa De Sousa - 94

Sumaré, SP, Nivel Municipal

Projeto Migrante Caminhando Para A Cidadania - 141

Suzano, SP, Nivel Municipal

Projeto Qualidade De Vida

Escolinhas Esportivas/ Escola Cidadania - 108

Suzano, SP, Nivel Estadual

Projeto Escola Recicla - 70

Tarumã, SP, Nivel Municipal

Projeto De Apoio Na Escola - 65

Projeto Renascer - 100

Teresina, PI, Nivel Municipal

Centro Da Juventude - 104

Projeto Cidadão - 103

Projeto Disque Idoso - 123

Projeto Vila-Bairro - 44

Teresina, PI, Nivel Estadual

Projeto Coral Nas Escolas - 114

Três Lagoas, MS, Nivel Municipal

Programa AABB Comunidade - 98

Programa Colo De Mãe - 95

Programa De Geração De Renda - 94

Programa Erradicação Do Trabalho Infantil - Peti De

Três Lagoas - 95

Programa Pão Da Semana - 95

Tupãssi, PR, Nivel Municipal

Projeto Capoeira na Escola - 69

Iniciação profissionalizante de Sala de Costura e

Mercenaria - 69

Três Passos, RS, Iniciativa Municipal

Programa Semeando Educação E Saúde Na

Agricultura Familiar - 108

Projeto Arte Viva - 108

Turmalina, MG, Nivel Municipal

Programa de Apoio à Criança e Ao Adolescente -110।

Projeto Capoeira Na Escola - 110
Projeto De Iniciação Ao Profissionalizante Sala De Costura E Mercenaria

Umuarama, PR, Nível Municipal

Projeto Núcleo das Artes - 83

Viamão, RS, Nivel Municipal

Curso De Formação Para Professores Cat Da Zona Rural - 63

Curso De Qualificação Para Profissionais Da Educação Infantil - 67

Educação De Jovens E Adultos - 66

Projeto De Educação Ambiental - 67

Viçosa Do Ceará, CE, Nível Municipal

Programa Criança Viçosa - 71

Vinhedo, SP, Nivel Municipal

Projeto Colibri - 47

Vitória, ES, Nivel Municipal

Arquitetura Social / Melhorias Habitacionais - 81

Campanha De Proteção Ao Caranguejo (Ucides Cordatus) - 48

Coleta Seletiva Comunidade E Catadores De Materiais Recicláveis -

Programa De Educação Ambiental - 37

Programa De Prevenção Das Dst/Aids E Uso Indevido De Drogas 115

Projeto Amigos Do Parque - 122

Projeto Cidadão Criança - 122

Projeto Terra - 137

Vitória, ES, Nivel Estadual

Programa De Planejamento De Ações De Segurança Pública - 91

Vitória Da Conquista, BA, Nivel Municipal

Central De Marcação De Consultas E Procedimentos - 75

Grupo De Economia Popular Do Municipio De Vitória Da Conquista $-140$

Volta Redonda, RJ, Nivel Municipal

Gestão Participativa E Descentralizada - 35

Iniciativa Unidade Básica Amiga Da Amamentação - 73

Politica De Avaliação De Desempenho Institucional - 40

Programa De Internação Domiciliar - 75

Projeto Agroambiental Da Comunidade - 136

Projeto Padaria Escola - 110

Projeto Ser Feliz - 109

Sistema De Informação Das Crianças E Adolescentes - 109

Trabalho Interdisciplinar Em Prol Da Humanização Na Unidade De

Cuidados Intensivos - 109 